\title{
Characterization and expression analysis of chymotrypsin after bacterial challenge in the mud crab, Scylla paramamosain
}

\author{
Jie Gong ${ }^{1}$, Yinjie Xie ${ }^{1}$, Kun Yu ${ }^{1}$, Ya'nan Yang ${ }^{1}$, Huiyang Huang ${ }^{1}$ and Haihui Ye $e^{1,2}$ \\ ${ }^{1}$ College of Ocean and Earth Sciences, Xiamen University, Xiamen, Fujian, China. \\ ${ }^{2}$ Center for Marine Biotechnology, Xiamen University, Xiamen, Fujian, China.
}

\begin{abstract}
Chymotrypsin is one of the serine proteases families that have various biological functions. A chymotrypsin gene was isolated from hepatopancreas of the mud crab, Scylla paramamosain (designated SpCHY) in this study. The full-length cDNA of SpCHY contained 942 nucleotides with a polyadenylation sequence and encoded a peptide of 270 amino acids with a signal peptide of 17 amino acids. The SpCHY gene contains seven exons, six introns, a TATA box and several transcription factor binding sites that were found in 5'-promoter region which is 1221 bp in length. Real-time quantitative PCR analysis indicated that the expression level of SpCHY mRNA in hepatopancreas was significantly higher than that in other tissues. Immunocytochemistry and in situ hybridization exhibited the $\mathrm{CHY}$-like reactivity presented in resorptive cells of the hepatopancreas. After bacterial challenge with Vibrio alginolyticus, the expression level of $S p C H Y$ mRNA was extremely up-regulated at $3 \mathrm{~h}$ in hepatopancreas. Our results suggest that $S p C H Y$ might play an important role in the mud crab's immune response.
\end{abstract}

Keywords: chymotrypsin, Scylla paramamosain, immune response, immunocytochemistry, in situ hybridization.

Received: August 21, 2013; Accepted: November 13, 2013.

\section{Introduction}

Belonging to one of the largest gene family in the animal kingdom, serine proteases (SP) have a tryp-spc domain, which is conserved with the catalytic triad (His, Asp and Ser), part of an extensive hydrogen bonding network (Szabo and Bugge, 2008; Zhou et al., 2012). In the human genome, approximate 500 protease-encoding genes have been identified, of which about $30 \%$ are SP or SP homologues (SPH) (Southan, 2001). In Drosophila melanogaster, around 200 SP- and SPH-encoding genes have been identified (Ross et al., 2003). SPs participate in various biological processes, including protein digestion (Mazumdar and Broadway, 2001; Broehan et al., 2008), immune response (Jiang et al., 2003a, b), and molting (Samuel and Reynolds, 1993; He et al., 2009).

As one of the SP, the chymotrypsin family includes chymotrypsin A and chymotrypsin B, two structurally related, but phylogenetically distinct subfamilies (Rawlings et al., 2008). Chymotrypsin B plays an important role in intracellular protein turnover, while chymotrypsin A is prevalent in the extracellular space and performs different functions (Broehan et al., 2010). The chymotrypsin A subfamily contains a variety of enzymes, such as chymotrypsin, trypsin, elastase, granzyme and different matrix

Send correspondence to Haihui Ye. College of Ocean and Earth Sciences, Xiamen University, Siming Nanlu No. 422, Xiamen, 361005 Fujian, China. E-mail: haihuiye @ xmu.edu.cn. peptidases, with different cleavage specificities. The substrate-binding pocket near the catalytic site determines these types of specificity (Perona and Craik, 1995). These proteins are all synthesized as inactive zymogens, which can be activated by specific proteolytic cleavage. The canonical catalytic triad residues (Ser, His and Asp) form the active site (Hedstrom, 2002).

In invertebrates, studies on chymotrypsin are mostly focused on the digestive system of some pest insects. In the lepidopteran, Spodoptera exigua, chymotrypsin was found likely to mediate the proteolytic remodeling in the gut during larval-pupal transition (Herrero et al., 2005). The injection of dsRNA for chymotrypsin $5 \mathrm{C} / 6 \mathrm{C}$ in the red flour beetle, Tribolium castaneum, resulted in severe molting defects, which indicate that chymotrypsin plays an important role in molting process (Broehan et al., 2010). In addition, chymotrypsin was associated with immune defense reactions against bacteria in D. melanogaster (de Morais et al., 2005). In crustaceans, only few studies report on chymotrypsin (Sellos and Wormhoudt, 1992; Shi et al., 2008; Serrano, 2013), and only few chymotrypsin cDNA and genomic DNA sequences have been cloned and characterized. The polymorphism and evolution of this gene have been analyzed in the pacific white shrimp, Litopenaeus vannamei (Sellos and Wormhoudt, 1992, 1999). Chymotrypsin in Chinese shrimp, Fenneropenaeus chinensis, was observed to be involved in innate immune reactions after bacterial and viral challenges (Shi et al., 2008). 
The mud crabs of the genus Scylla are important cultured crustaceans that live in intertidal and subtidal sheltered soft-sediment habitats (Keenan, 1999). In Southeast Asia, mud crabs are a valuable source of income for coastal communities (Le Vay, 2001; Ye et al., 2011). The bacterium, Vibrio alginolyticus, can cause many diseases (such as exoskeleton ulcer disease, black gill disease) that seriously affect crustacean aquaculture and thus receive increasing attention in recent years (Zhu et al., 2008).

In this study, we first cloned the cDNA, 5-promoter region and genomic DNA of a chymotrypsin gene from the mud crab, Scylla paramamosain (designated $S p C H Y$ ), and investigated its expression in various tissues by real-time quantitative PCR. The localization of chymotrypsin protein and mRNA in hepatopancreas was detected by immunocytochemistry and in situ hybridization. The temporal responses of $\mathrm{SpCHY}$ to the bacterium $V$. alginolyticus were investigated to study the role of $\mathrm{SpCHY}$ in the immune response.

\section{Materials and Methods}

\section{Sample collection}

Vigorous female crabs ( $\sim 250 \mathrm{~g})$, with both claws intact and antennae in movement, were purchased from a local fish market in Xiamen city, China. Brain, thoracic ganglion, heart, gill, hepatopancreas, stomach, muscle, and ovary tissues were dissected and immediately preserved in liquid nitrogen. Total RNA was extracted using Trizol reagent (Invitrogen, USA) according to the manufacturer's protocol and potential genomic contamination was re- moved by DNase I treatment. RNA quality was determined by agarose gel electrophoresis and quantification was done with an ND-1000 NanoDrop UV spectrophotometer (NanoDrop Technologies, USA). RNA aliquots of $1 \mu \mathrm{g}$ were reversely transcribed using a reversed first strand cDNA synthesis kit (Fermentas, USA) and stored at $-20^{\circ} \mathrm{C}$.

\section{Cloning of full-length SpCHY cDNA}

The degenerate primers CHYf1 and CHYr1 (Table 1), directed to highly conserved sequences of various chymotrypsin orthologs, were used to amplify a partial chymotrypsin-like sequence of $S$. paramamosain. The $S p C H Y$ sequence was completed by 3 ' and 5 ' rapid amplification of cDNA ends (RACE) by means of a 3', 5' full race kit (Takara, Dalian, China). The specific primers $C H Y 3^{\prime}$ and CHY5' are listed in Table 1.

Polymerase chain reactions (PCR) were carried out in a total volume of $25 \mu \mathrm{L}$ that contained $1 \mu \mathrm{L}$ of cDNA template, $2.5 \mu \mathrm{L}$ of $10 x$ PCR buffer (containing $\mathrm{Mg}^{2+}$ ), $1 \mu \mathrm{L}$ of each primer $(10 \mu \mathrm{M}), 2.5 \mu \mathrm{L}$ of dNTP $(2.5 \mathrm{mM}), 0.2 \mu \mathrm{L}$ (2.5 U) of LA Taq polymerase (Takara, Dalian, China) and $16.8 \mu \mathrm{L}$ of PCR-grade water. PCR conditions were as follows: $94{ }^{\circ} \mathrm{C}$ for $3 \mathrm{~min} ; 32$ cycles of $94{ }^{\circ} \mathrm{C}$ for $30 \mathrm{~s}, 58^{\circ} \mathrm{C}$ for $30 \mathrm{~s}$ and $72{ }^{\circ} \mathrm{C}$ for $1 \mathrm{~min}$; followed by a final extension at $72{ }^{\circ} \mathrm{C}$ for $10 \mathrm{~min}$. After agarose gel electrophoresis, the DNA fragment of expected size was ligated into pMD19-T vectors (Takara, Dalian, China) and then used to transform competent cells of Escherichia coli. Positive recombinant clones were sequenced using the specific primers RV-M

Table 1 - Summary of primers used in this study.

\begin{tabular}{|c|c|c|c|}
\hline Primer name & Primer Sequence (5'- 3') & Purpose & Amplified fragment length \\
\hline CHYf1 & GGYGTYGTYTGCATYGACGGHRC & fragment amplication & $203 \mathrm{bp}$ \\
\hline CHYr1 & GCTCAGGGWKTGACRCCRGTCTT & fragment amplication & \\
\hline CHY3' & CTCGCTCTGCTCCTTGTCTG & 3' amplication & 904 bp \\
\hline CHY5 & GAAAGATGTGATGCCGTAGGTC & 5' amplication & $728 \mathrm{bp}$ \\
\hline CHYf2 & ATGATTGCCAAGCTCGCTCTG & genomic DNA amplify & 1994 bp \\
\hline $\mathrm{CHY \textrm {r } 2}$ & TCAGGGGGTGACACCGGTC & genomic DNA amplify & \\
\hline CHYf3 & ACGAGCAGGGACTTCTTCACC & real-time RT-PCR for $\mathrm{SpCHY}$ & $286 \mathrm{bp}$ \\
\hline $\mathrm{CHY} 3$ & AGACGACGCCACTTCCAACA & real-time RT-PCR for $\mathrm{SpCHY}$ & \\
\hline CHY5-1 & CAGCAACGCAGACAAGGAGCA & promoter region clone & $1261 \mathrm{bp}$ \\
\hline CHY5-2 & TGGGGAAAGAAGGAAAGTGGC & promoter region clone & $1155 \mathrm{bp}$ \\
\hline CHY5-3 & GCAAAACATCTACGACCACAGCA & promoter region clone & 974 bp \\
\hline TCHYf1 & GCCAGAACGAGCCCTCTCAG & riboprobe amplication clone & $314 \mathrm{bp}$ \\
\hline $\mathrm{TCHY \textrm {r } 1}$ & GACGACGCCACTTCCAACAAT & riboprobe amplication clone & \\
\hline $\mathrm{T} 7$ & TAATACGACTCACTATAGGG & riboprobe amplication clone & \\
\hline M13-47 & CGCCAGGGTTTTCCCAGTCACG & colony PCR & \\
\hline RV-M & GAGCGGATAACAATTTCACACA & colony PCR & \\
\hline$\beta$-actin $F$ & GAGCGAGAAATCGTTCGTGAC & internal control & $183 \mathrm{bp}$ \\
\hline$\beta$-actin $\mathrm{R}$ & GGAAGGAAGGCTGGAAGAGAG & internal control & \\
\hline
\end{tabular}


and M13-47 (Table 1) at Sangon Biotech Co, Ltd (China). Finally, the full-length of $\mathrm{SpCHY}$ cDNA was assembled from 3' end and 5' end sequences.

\section{Genomic DNA and promoter cloning of $\mathrm{SpCHY}$}

Genomic DNA was extracted from muscle tissue of the mud crab by means of a DNA extraction kit (Takara, Dalian, China) PCR amplified by two specific primers CHYf2 and CHYr2 (Table 1) PCR and cloned as described above. The promoter region was cloned by genome walking using the Universal Genome Walker kit (Takara, Dalian, China). Nested PCR was performed with primers CHY5-1, CHY5-2, CHY5-3 (Table 1) according to the manufacturer's protocol. The PCR product was purified and sequenced as before.

\section{Phylogenetic and sequence analysis of $\mathrm{SpCHY}$}

A homology analysis of $S p C H Y$ with $C H Y$ genes of other species was performed using the Blastp algorithm. Characteristics of the protein were predicted using algorithms.of the Expasy site. The putative signal peptide was identified with SignalP software (Nielsen et al., 1997), and the ClustalW program was used to perform multiple sequence alignments. The neighbor-joining method implemented in MEGA3.1 software was used to construct the phylogenetic tree based on protein sequences (Kumar et al., 2004), with a bootstrapping replication of 1000 . SSRHunter software was used to search for microsatellite sequences.

\section{Tissue expression of $\mathrm{SpCHY}$}

mRNA transcripts of $S p C H Y$ in different tissues were examined by real-time quantitative PCR (Applied Biosystems 2770 Thermal Cycle, New York, USA). The reactions were performed in a $20 \mu \mathrm{L}$ reaction volume containing $10 \mu \mathrm{L}$ of SYBR premix, $2 \mu \mathrm{L}$ of cDNA template $(1 / 10 \mathrm{x}$ dilution of cDNA), $0.8 \mu \mathrm{L}$ of each primer (10 $\mu \mathrm{M}$ CHYf3 and $C H Y$ r3; Table 1) which amplify a product of $286 \mathrm{bp}$, and $6.4 \mu \mathrm{L}$ of PCR-grade water. PCR conditions were as follows: $94{ }^{\circ} \mathrm{C}$ for $10 \mathrm{~min} ; 40$ cycles of $94^{\circ} \mathrm{C}$ for $20 \mathrm{~s}, 56^{\circ} \mathrm{C}$ for $30 \mathrm{~s}$ and $72{ }^{\circ} \mathrm{C}$ for $40 \mathrm{~s}$; final extension at $72{ }^{\circ} \mathrm{C}$ for 10 min. A 183 bp $\beta$-actin (GU99242) fragment of $S$. paramamosain was amplified as the internal control. Standard curves were run for each primer and the cDNA templates were tested in a graded dilution series $(1,1 / 10,1 / 100$, $1 / 1000)$. Based on these analyses, PCR efficiency was calculated to be $>96 \%$ (according to the PCR amplification formula $\mathrm{E}=10^{(-1 / \text { slope })}-1$; where $\mathrm{E}$ is the PCR efficiency). The negative control was performed with PCR-grade water replacing the cDNA template. All samples were run in triplicate and relative expression was calculated as $2^{-\Delta \Delta \mathrm{Ct}}$ (Livak and Schmittgen, 2001).

\section{Immunocytochemistry}

Hepatopancreas tissue removed from adult female crabs was fixed in Bouin's fixative overnight, dehydrated, embedded in paraffin, and then sectioned at $7 \mu \mathrm{m}$ thickness. The sections were immunocytochemically stained by the streptavidin-peroxidase method with a primary antiserum generated in mouse against CHY (1:100 dilution, Abcam, UK) following an immunocytochemical protocol of the supplier (Transgen, China). The presence of CHY-like immunoreactivity in the tissues was visualized by a DAB enhanced liquid substrate system (Sigma-Aldrich, USA). Thereafter, the sections were dehydrated and observed on an Olympus multifunction microscope BX51 (Olympus, Japan). Control sections were prepared simultaneously by substituting PBS buffer solution in place of the primary antibody.

\section{In situ hybridization}

Digoxigenin-labeled cRNA riboprobes were synthesized with a DIG-RNA labeling Kit (Roche, Switzerland) using a $314 \mathrm{bp}$ template of $S p C H Y$ that was ligated into the pGEM-T easy vector (Promega, USA). Hepatopancreas tissue was dissected and immediately fixed overnight in $4 \%$ paraformaldehyde (PFA) in phosphate-buffered saline (PBS) made in diethypyrocarbonate (DEPC) water. Tissue sections of $7 \mu \mathrm{m}$ thickness were hybridized with the digoxigenin-labeled riboprobes at $57^{\circ} \mathrm{C}$ overnight followed by incubation in an anti-DIG alkaline phosphatase-conjugated antibody (Roche, Switzerland). Hybridization signals were visualized with the colorimetric substrates nitroblue tetrazolium/4-bromo-4-chloro-30-indolylphosphate

(NBT/BCIP). The riboprobe templates for $\mathrm{SpCHY}$ were generated by RT-PCR from hepatopancreas cDNA using the specific primers TCHYf1, TCHYr1 containing $T 7$ adapters. Photographs were taken on an Olympus multifunction microscope BX51 (Olympus, Japan).

\section{Temporal expression of SpCHY in hepatopancreas after immune challenge}

In an attempt to determine whether $S p C H Y$ was involved in innate immune reactions, the expression profiles of $S p C H Y$ after bacterial challenge were measured and compared to the unchallenged (control group). The bacterium $V$. alginolyticus was prepared and washed for animal challenge. A dose of $1 \times 10^{7} \mathrm{CFU}$ mixed with $20 \mu \mathrm{L}$ crab saline was injected at the base of the last pereiopods into each of 30 vigorous female crabs $(\sim 250 \mathrm{~g})$ of the experimental group (Cheng et al., 2004). Another 30 vigorous female crabs $(\sim 250 \mathrm{~g})$ composing the control group were injected with $20 \mu \mathrm{L}$ saline. These two groups were reared separately in culture tanks under the same conditions with seawater at a temperature between $26-28^{\circ} \mathrm{C}$, salinity at $26 \mathrm{ppt}$, and with continuous aeration. For real-time quantitative PCR assays, three crabs each were sampled at $0,3,6,12,24,48$ and $72 \mathrm{~h}$ post-injection and their hepatopancreas tissues were dissected and preserved in RNAsafer Stabilizer Reagent (Takara, Dalian, China). Total RNA extraction, first-strand 
cDNA synthesis and real-time quantitative assays were performed according to the procedures described above.

\section{Statistical analysis}

One-way analysis of variance (ANOVA) and Student's t-test done with SPSS 11.5 software were used to determine the statistical significance of $S p C H Y$ expression in different tissues and challenge experiment respectively (SPSS, Chicago, IL, USA). Before the comparisons, Kolmogorov-Smirnov and Cochran tests were run to test for normality and homogeneity of variances. P values of $<0.05$ were considered statistically significant.

\section{Results}

\section{Cloning of the SpCHY gene}

A 942 bp cDNA sequence of $S p C H Y$ (GenBank accession number: JF831535.1) was obtained in this study. It comprises an $813 \mathrm{bp}$ open reading frame (ORF) encoding 270 amino acids with a signal peptide of 17 amino acids, an 115 bp 3'-untranslated region (UTR) with a polyA tail, and a $14 \mathrm{bp} \mathrm{5'UTR} \mathrm{(Figure} \mathrm{1).} \mathrm{The} \mathrm{deduced} \mathrm{molecular} \mathrm{weight}$ of mature $\mathrm{SpCHY}$ protein was $28.5 \mathrm{kDa}$ and its isoelectric point 6.11. Conserved domain analysis done online in NCBI showed that SpCHY contained a trypsin-like SP domain including one cleavage site I-45, three active site (H-85, D-131, S-222), three substrate binding sites (S-216, S-237, G-239), and six cysteine residues, which were similar to other chymotrypsin members.

Similar to other chymotrypsin genes, $\mathrm{SpCHY}$ is composed of seven exons interrupted by six introns. In addition, all the intron-exon boundaries conformed to the GT-AG rule, which belonged to a 0-type intron/exon junction. Moreover, a $36 \mathrm{CA}$ repeat microsatellite sequence was found by screening with SSRHunter software (Figure 2).

In order to study the regulation of $\mathrm{SpCHY}$ expression in the mud crab, we used a cloned $1221 \mathrm{bp}$ fragment of the 5 ' flanking region of the $S p C H Y$ gene. Using the program Promoter 2.0, we found a putative TATA box that was located at $45 \mathrm{bp}$ upstream of the translation start site. In addition, several putative transcriptional factor binding sites or cis-regulatory elements including HSF, Hb, Dfd, SP1, Bcd, CF1 and Ubx were also identified.

\section{Phylogenetic analysis of $\mathrm{SpCHY}$}

Blastp data showed that the deduced amino acid sequence shared high similarity with chymotrypsins of $L$. vannamei CHYA (GenBank accession no. CAA71672, 82\%), F. chinensis (ACC68669.1, 80\%), M. japonicus (BAI49929.1, 79\%), $L$. vannamei CHYB (CAA71673.1, $79 \%)$. The phylogenetic analysis suggested that three different groups were formed, representing CHYs from invertebrates, vertebrates and urochordates respectively. The vertebrate $\mathrm{CHY}$ group could be further separated into three distinct and well-supported clades: CHYA, CHYB, and CHYC (caldecrin). The invertebrate group contained 2 subgroups. As showed in Figure 3, crustacean CHY was well separated from insect CHY and formed a separate cluster.

\section{Tissue distribution of SpCHY mRNA}

Real-time quantitative PCR showed that $\mathrm{SpCHY}$ mRNA is expressed in a wide variety of tissues, including

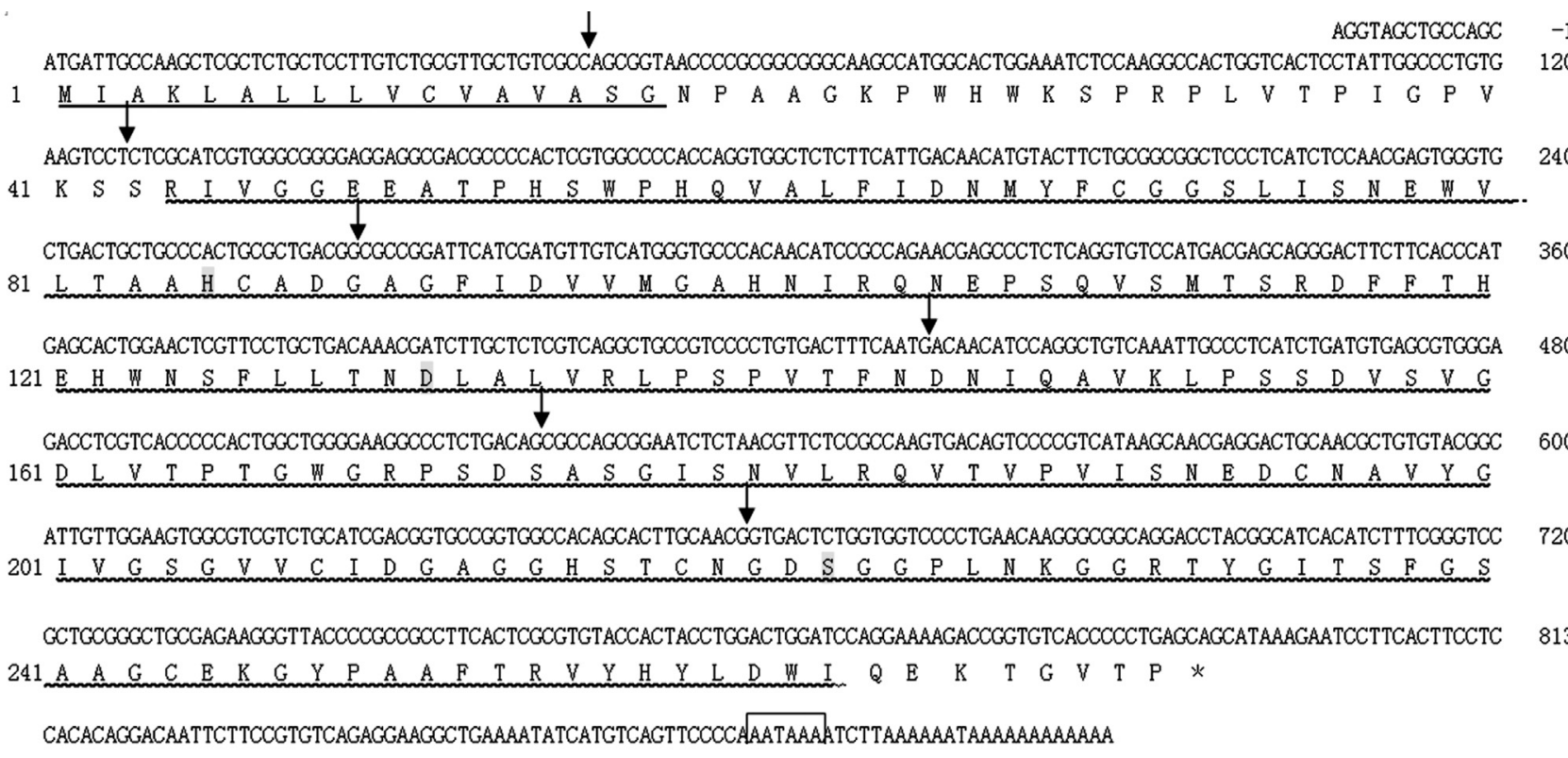

Figure 1 - Nucleotide and deduced amino acid sequences of the $S p C H Y$ gene (GenBank accession no. JF831535.1). The nucleotides are numbered on the right, and the amino acids on the left. The putative signal peptide is underlined. The trypsin-like SP domain is wave underlined. The catalytic triad (H, D, and $\mathrm{S}$ ) is gray shadowed. The boxed letters are the polyadenylation signal. The asterisk $\left(^{*}\right)$ indicates the stop codon and arrows indicate the location of introns. 
Exon

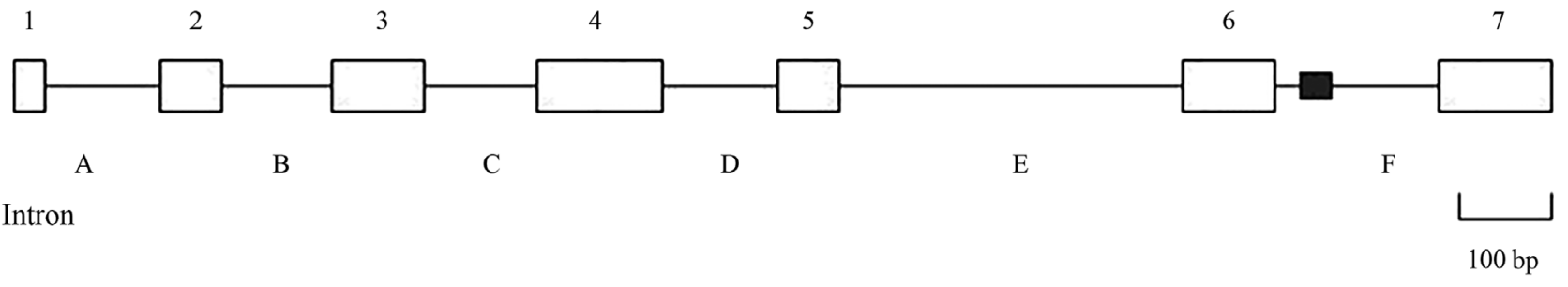

Figure 2 - Organization of the $S p C H Y$ gene. The positions of the exons (open boxes 1-7), introns (A-F), and CA repeat sequence (filled box) are denoted.

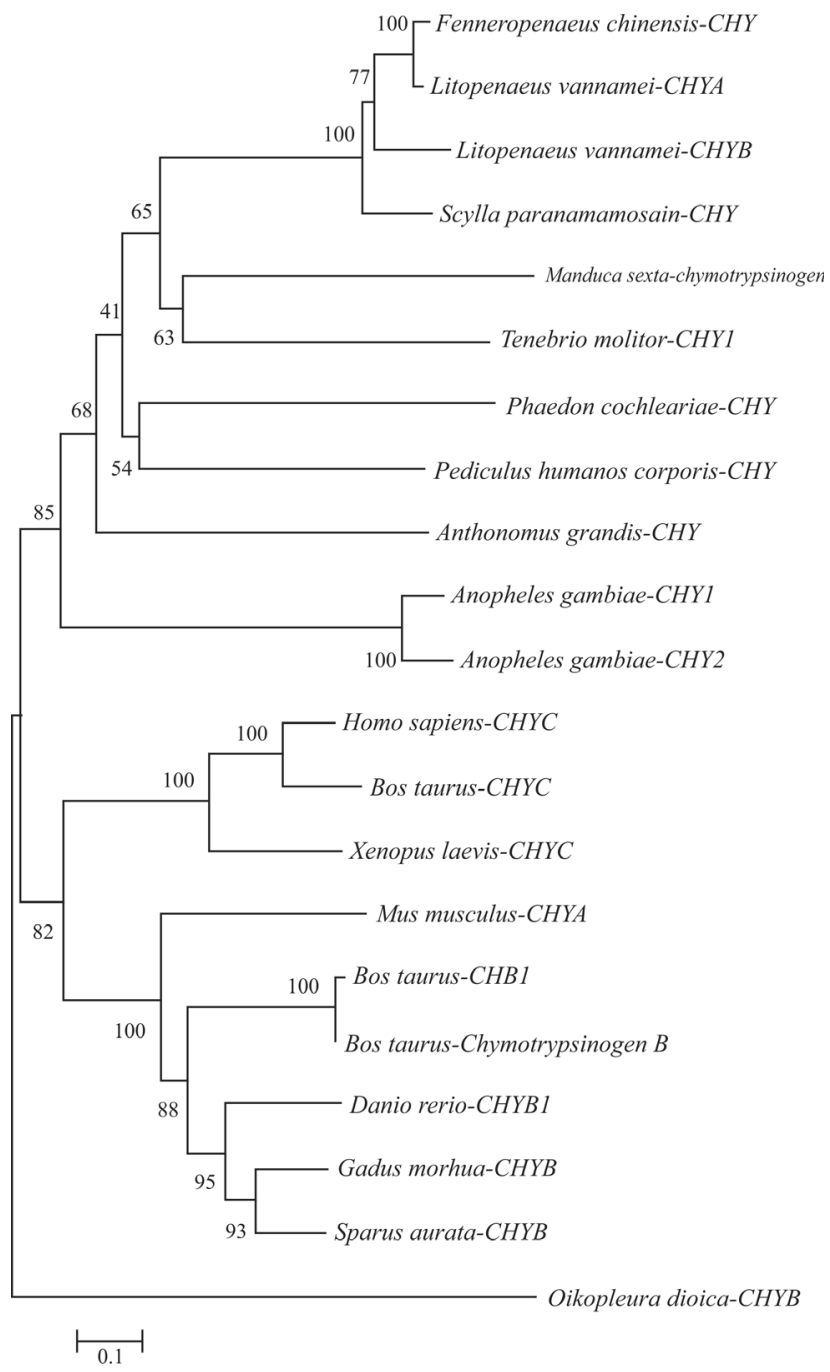

Figure 3 - Phylogenetic analysis of SpCHY with other chymotrypsins. A NJ tree was produced with Mega3.1 software. One thousand bootstraps were carried out to check the repeatability of the result. L. vannameiCHYA (CAA71672), L. vannamei-CHYB (CAA71673), F. chinensisCHY (ACC68669), P. humanus corporis-CHY (AAV68346), $P$. cochleariae-CHY (CAA76928), T. molitor-CHY (DQ356031.1), M. sexta-CHY (2120321A), A. grandis-CHY (AAT09847.1), A. gambiaeCHY1 (CAA79325), A. gambiae-CHY2 (CAA79326), B. Taurus - CHYB (P00767), G. morhua-CHYB (P80646), S. aurata-CHYB (AAT45258), M. musculus-CHY (AAL11034), H. sapiens-CHY (CAA74031.1), B. taurus-CHYC(AAI51507.1), $X$. laevis-CHYC(NP_001085458), $B$. taurus-CHYB (NP_001098800.1), D. rerio-CHYB1 (NP_997783.1), and O. dioica-CHYB (AAT47850). brain, thoracic ganglion, heart, gill, hepatopancreas, stomach, muscle, and ovary. The mRNA expression level in hepatopancreas was considerably higher than that of other tissues, with the expression level in muscle being the lowest (Figure 4).

\section{Immunocytochemistry and in situ hybridization}

The histological results showed that hepatopancreas of $S$. paramamosain consists of many blind ending tubules (hepatopancreatic tubules). The hepatopancreas cells could be classified into four types: embryonic cells, fibrillar cells, resorptive cells, and blister cells (Figure 5A).

Using immunocytochemistry, SpCHY protein was detected in resorptive cells of the hepatopancreas, and the positive signals were mottled (Figure 5B). SpCHY gene expression was determined by in situ hybridization. Positive hybridization signals with the antisense $S p C H Y$ riboprobe were also mainly localized in resorptive cells (Figure 5C). However, specific signals were also detected in some small cells around the blind ending tubules. No positive signal was detected with the sense $S p C H Y$ riboprobe in hepatopancreas (Figure 5D).

\section{Expression of $\mathrm{SpCHY}$ in hepatopancreas following bacterial challenge}

In order to determine whether $S p C H Y$ may be involved in innate immune reactions, the expression profiles of $\mathrm{SpCHY}$ after bacterial challenge were evaluated. Total

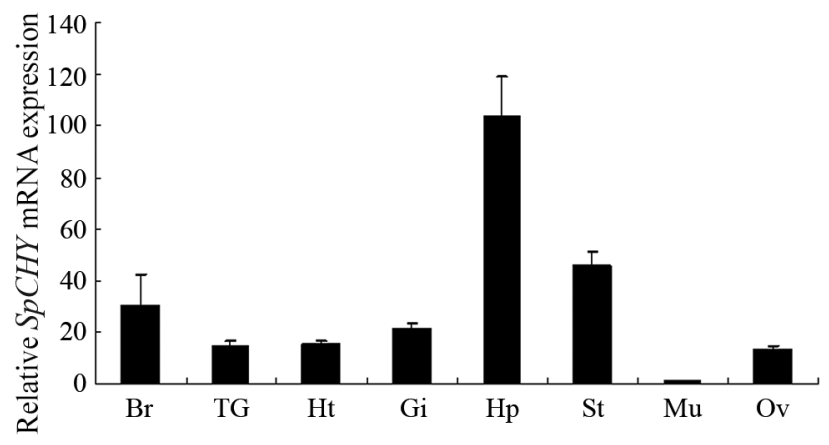

Figure 4 - The results of quantitative real-time PCR analysis of $S p C H Y$ expression in various tissues. Expression of a $\beta$-actin gene was used as control. Values were shown as means \pm S.E. $(\mathrm{N}=3)$. Abbreviations: $\mathrm{Br}$, brain; TG, thoracic ganglion; Ht, heart; Gi, gill; Hp, hepatopancreas; St, stomach; Mu, muscle; Ov, ovary. 


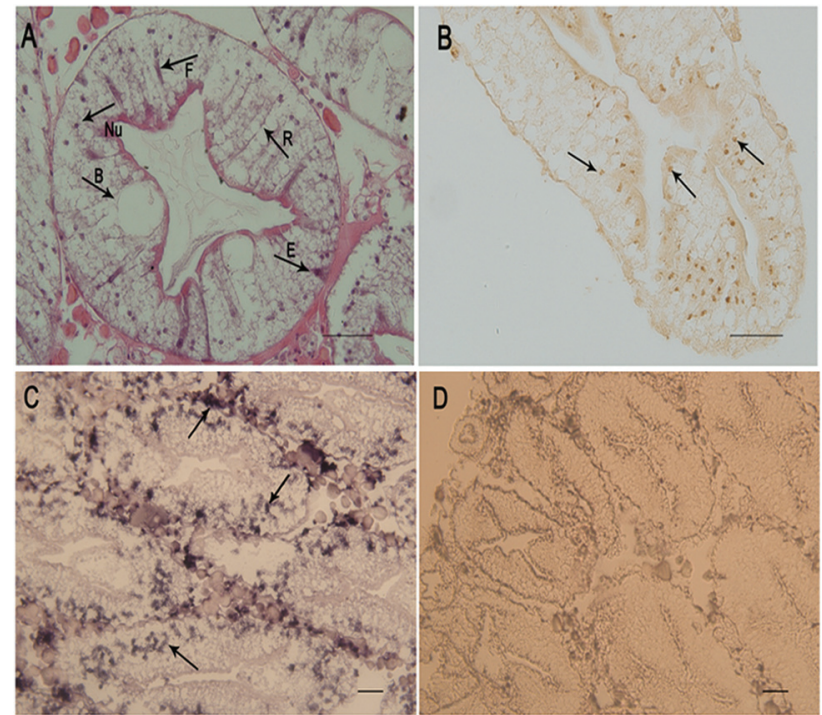

Figure 5 - Location of $S p C H Y$ by immunocytochemistry and in situ hybridization in hepatopancreas of S. paramamosain. (A) histological observation; R resorptive cells, B blister cells, E embryonic cells, F fibrillar cells, Nu nucleus. (B) immunocytochemistry results; the arrows point to immunocytochemical positive signals. (C) in situ hybridization results; arrows indicate the specific $S p C H Y$ mRNA hybridization signal with the antisense riboprobe. (D) The negative control with the sense riboprobe showed no specific signal. Scale bars: $50 \mu \mathrm{m}$.

hepatopancreas RNA was extracted from control and bacterial challenged crab at $0,3,6,12,24,48$ and $72 \mathrm{~h}$. Compared to the control group, in crabs injected with the bacterium $V$. alginolyticus the $S p C H Y$ mRNA expression level increased distinctly about 20 -fold at $3 \mathrm{~h}(\mathrm{p}<0.01)$ and then decreased to normal level (Figure 6). During this $72 \mathrm{~h}$ time interval $S p C H Y$ expression levels in the control group fluctuated slightly but not significantly.

\section{Discussion}

In present study, a new chymotrypsin gene was identified from the mud crab, S. paramamosain, and was designated as $S p C H Y$. The full-length cDNA contained an $813 \mathrm{bp}$ open reading frame which encoded a putative chymotrypsin of 270 amino acids. The putative amino acids sequence has high identity with the other known crustacean chymotrypsins such as L. vannamei and $F$. chinensis. ClustalX alignment of the $\mathrm{CHY}$ sequence revealed that the tryp-spe domain was conserved among arthropod chymotrypsins. In addition, the catalytic triad $(\mathrm{H}, \mathrm{D}, \mathrm{S})$ characteristic of chymotrypsins was observed in the deduced amino sequence. Furthermore, three disulfide bonds formed by six cysteines were found at the same location as in other chymotrypsins. This indicates the importance of secondary structure conservation for the enzymatic activity of this family. Another free cysteine residue found in the signal peptide was also identical to chymotrypsins from other invertebrates. The high similarity, together with the conser-

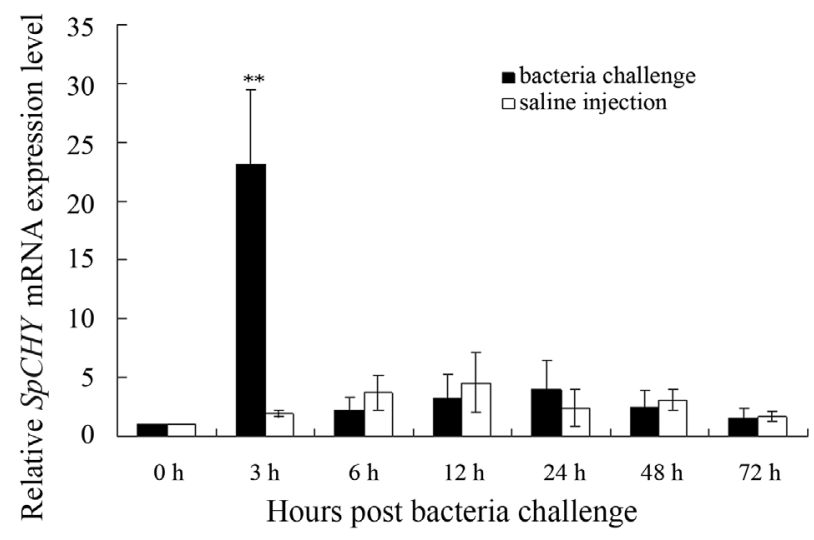

Figure 6 - Transcript profiles of $S p C H Y$ in hepatopancreas of $S$. paramamosain following challenge with $V$. alginolyticus,. The relative $S p C H Y$ transcript levels in crabs challenged with $V$. alginolyticus were compared to those of saline injected animals. The expression of a $\beta$-actin gene was used as endogenous control. Significant differences of $\mathrm{SpCHY}$ expression between the challenged and the control group are indicated with asterisks. ${ }^{*} \mathrm{p}<0.01$.

vation of tryp-spc domain and catalytic triad, indicated that $S p C H Y$ is a true member of the chymotrypsin family.

The genomic sequence of $S p C H Y$, here first reported in crabs, is composed of seven exons and six introns, with the first intron inserted near the end of the putative signal peptide. The locations of introns were almost the same as in the white shrimp, L. vannamei, chymotrypsin gene (Sellos and Wormhoudt, 1992). The active site residues (His85, Asp131 and Ser222) involved in catalysis, as well as the residues (Ser216, Ser237 and Gly239) forming the binding pocket to interact with the hydrophobic side chains of the substrate, were encoded by separate exons. These functionally important amino acids and binding regions in separate exons are typical for the $S P$ genes that have been described (Swift et al., 1984; Craik et al., 1984). Hence, the joining of different exons, encoding intrinsically catalytically inactive protein segments, resulted in the substrate specificity and catalytic activity of the enzyme. Moreover, the similarity between $S p C H Y$ and other $S P$ genes in the number and location of intron/exon junctions revealed an evolutionary conservation of chymotrypsin gene.

In our study, $\mathrm{SpCHY}$ expression was detected in various tissues and strongly so in hepatopancreas. The high expression level of $\mathrm{SpCHY}$ in hepatopancreas was consistent with the role of the hepatopancreas as the main site for synthesizing digestive enzymes in crustaceans (Shi et al., 2008). Furthermore, crustacean hepatopancreas plays important roles in initiating humoral immunity and mediating cellular immune responses performed by certain specialized cells and phagocytes (Gross et al., 2001), which is supported by the discovery of several immunity-related genes in crustacean hepatopancreas post bacterial infection (Pan et al., 2005; Zhao et al., 2007).

The results obtained by immunocytochemistry and in situ hybridization indicated that the hepatopancreas is the 
site of expression and translation of SpCHY. CHYimmunoreactivity was found in resorptive cells, supplying morphological evidence for the secretory function of resorptive cells. The localization of $S p C H Y$ mRNA in resorptive cells by in situ hybridization further strengthens this conclusion. All these findings indicated that $\mathrm{SpCHY}$ is synthesized in resorptive cells and might be secreted to implement the digestive and immune roles.

Lacking an acquired specific immune system, the innate immune system in crustaceans is considered as the major microbial infection defense mechanism (Chaikeeratisak et al., 2012; Kiruthiga et al., 2012). In recent years, nonspecific immune system has been found to be of equal importance as a specific immune system, especially for the production of anti-bacterial and anti-viral proteins (Liu et al., 2010). Pathogen molecules can trigger these immune responses by pattern recognition proteins (PRPs) (Medzhitov and Janeway, 1997). These PRPs bind to microbes and then activate the prophenoloxidase system (proPOsystem), stimulate the release of antimicrobial peptides (AMPs), or initiate other biological defense processes. Recently, the clip domain SP was demonstrated to be cofactor for the activation of the proPO cascade in invertebrates (Cerenius and Söderhäll, 2004; Gai et al., 2009). For example, in Sydney rock oysters, Saccostrea glomerata, the increase in chymotrypsin could activate ProPO to PO (Aladaileh et al., 2007).

The immune function of chymotrypsin has been reported in F. chinensis (Shi et al., 2008). However, little research has focused on the function of innate immunity in crabs. In this study, $\mathrm{SpCHY}$ was strongly up-regulated in $S$. paramamosain at $3 \mathrm{~h}$ after infection with the bacterium $V$. alginolyticus. In appropriate hosts, this kind of bacteria could proliferate unceasingly. The infection caused by unceasing reproduction of bacteria could induce the formation of reactive oxygen species (ROS) and severely destroy the functionality of crab cells (Li et al., 2011). Similar results showing that $\mathrm{SpCHY}$ expression is significantly shortly after bacterial infection were also obtained in other crustaceans (Amparyup et al., 2007; Qin et al., 2009; Cui et al., 2010). Hence we hypothesize that increasing the expression of $\mathrm{SpCHY}$ could activate PO production triggering an immune response and killing the bacteria.

In conclusion, our data suggest clearly for the first time that $\mathrm{SpCHY}$ is involved in the immune reaction against invading bacteria in the mud crab, S. paramamosain. The result should be helpful to understand the antibacterial defense mechanisms of crabs and provide biological information for mitigating crab diseases. Notwithstanding, the exact role of $\mathrm{SpCHY}$ in the activation of the immune response cascade needs further investigation.

\section{Acknowledgments}

This work was funded by grants from the National Natural Science Foundation of China (No. 41076081,
31272632) and the Innovative Research Funds in Xiamen University (No. 201112G009).

\section{References}

Amparyup P, Jitvaropas R, Pulsook N and Tassanakajon A (2007) Molecular cloning, characterization and expression of a masquerade-like serine proteinase homologue from black tiger shrimp Penaeus monodon. Fish Shellfish Immunol 22:535-546.

Aladaileh S, Rodney P, Nair SV and Raftos DA (2007) Characterization of phenoloxidase activity in Sydney rock oysters (Saccostrea glomerata). Comp Biochem Physiol B 148:470-480.

Broehan G, Kemper M, Driemeier D, Vogelpohl I and Merzendorfer H (2008) Cloning and expression analysis of midgut chymotrypsin-like proteinases in the tobacco hornworm. $\mathrm{J}$ Insect Physiol 54:1243-1252.

Broehan G, Arakane Y, Beeman RW, Kramer KJ, Muthukrishnan S and Merzendorfer H (2010) Chymotrypsin-like peptidases from Tribolium castaneum: A role in molting revealed by RNA interference. Insect Biochem Mol Biol 40:274-283.

Cerenius L and Söderhäll K (2004) The prophenoloxidaseactivating system in invertebrates. Immunol Rev 1981:16-26.

Chaikeeratisak V, Somboonwiwat K, Wang HC, Lo CF and Tassanakajon A (2012) Proteomic analysis of differentially expressed proteins in the lymphoid organ of Vibrio harveyiinfected Penaeus monodon. Mol Biol Rep 39:6367-6377.

Cheng W, Liu CH, Ye ST and Chen JC (2004) The immune stimulatory effect of sodium alginate on the white shrimp Litopenaeus vannamei and its resistance against Vibrio alginolyticus. Fish Shellfish Immunol 17:41-51.

Craik CS, Choo QL, Swift GH, Quinto C, MacDonald RJ and Rutter WJ (1984) Structure of two related rat pancreatic trypsin genes. J Biol Chem 259:14255-14264.

Cui ZX, Liu Y, Wu DH, Luan WS, Wang SY, Li QQ and Song CW (2010) Molecular cloning and characterization of a serine proteinase homolog prophenoloxidase-activating factor in the swimming crab Portunus trituberculatus. Fish Shellfish Immunol 29:679-686.

Gai YC, Qiu LM, Wang LL, Song LS, Mu CK, Zhao JM, Zhang Y and Li L (2009) A clip domain serine protease (cSP) from the Chinese mitten crab Eriocheir sinensis: cDNA characterization and mRNA expression. Fish Shellfish Immunol 27:670-677.

Gross PS, Bartlett CL, Browdy CL, Chapman RW and Warr GW (2001) Immune gene discovery by expressed sequence tag analysis of hemocytes and hepatopancreas in the pacific white shrimp, Litopenaeus vannamei, and the atlantic white shrimp, L. setiferus. Dev Comp Immunol 25:565-577.

Hedstrom L (2002) Serine protease mechanism and specificity. Chem Rev 102:4501-4524.

Herrero S, Combes E, Van OMM, Vlak JM, deMaagd RA and Beekwilder J (2005) Identification and recombinant expression of a novel chymotrypsin from Spodoptera exigua. Insect Biochem Mol Biol 35:1073-1082.

He WY, Zheng YP, Tang L, Zheng SC, Beliveau C, Doucet D, Cusson M and Feng QL (2009) Cloning, expression and localization of a trypsin-like serine protease in the spruce budworm, Choristoneura fumiferana. Insect Sci 16:455464. 
Jiang H, Wang Y, Yu XQ, Zhu Y and Kanost MR (2003a) Prophenoloxidase-activating proteinase-2 (PAP-2) from hemolymph of Manduca sexta: A bacteria-inducible serine proteinase containing two clip domains. J Biol Chem 278:3552-3561.

Jiang H, Wang Y, Yu XQ, Zhu Y and Kanost MR (2003b) Prophenoloxidase-activating proteinase-3 (PAP-3) from Manduca sexta hemolymph: A clip-domain serine proteinase regulated by serpin-1 $\mathrm{J}$ and serine proteinase homologs. Insect Biochem Mol Biol 33:1049-1060.

Keenan C (1999) Aquaculture of mud crab, genus Scylla - past, present and future. In: Keenan $\mathrm{C}$ and Blackshaw (eds) A Mud Crab Aquaculture and Biology. ACIAR Proceedings, No. 78. Watson Ferguson and Company, Canberra, pp 9-13.

Kiruthiga C, Rajesh S, Rashika V, Priya R and Narayanan RB (2012) Molecular cloning, expression analysis and characterization of peroxiredoxin during WSSV infection in shrimp Fenneropenaeus indicus. J Invert Pathol 109:52-58.

Kumar S, Tamura K and Nei M (2004) MEGA3: Integrated software for molecular evolutionary genetics analysis and sequence alignment. Brief Bioinform 5:150-163.

Le Vay L (2001) Ecology and management of mud-crab Scylla spp. Asian Fish Sci 14:101-112.

Li JT, Chen P, Liu P, Gao BQ, Wang QY and Li J (2011) Molecular characterization and expression analysis of extracellular copper-zinc superoxide dismutase gene from swimming crab Portunus trituberculatus. Mol Biol Rep 38:2107-2115.

Liu HP, Chen RY, Zhang M and Wang KJ (2010) Isolation, gene cloning and expression profile of a pathogen recognition protein: A serine proteinase homolog $(\mathrm{Sp}-\mathrm{SPH})$ involved in the antibacterial response in the crab Scylla paramamosain. Dev Comp Immunol 34:741-748.

Livak KJ and Schmittgen TD (2001) Analysis of relative gene expression data using real time quantitative PCR and the 2 (-Delta Delta C (T)) method. Methods 25:402-408.

Mazumdar LS and Broadway RM (2001) Identification of six chymotrypsin cDNAs from larval midguts of Helicoverpa zea and Agrotis ipsilon feeding on the soybean Kunitz trypsin inhibitor. Insect Biochem Mol Biol 31:633-644.

Medzhitov R and Janeway CA (1997) Innate immunity: The virtues of a nonclonal system of recognition. Cell 91:295-298.

de Morais GS, Vitorino R, Domingues R, Tomer K, Correia AJF, Amado F and Domingues P (2005) Proteomics of immunechallenged Drosophila melanogaster larvae hemolymph. Biochem Biophys Res Commun 328:10-15.

Nielsen H, Engelbrecht J, Brunak S and vonHeijne G (1997) Identification of prokaryotic and eukaryotic signal peptides and prediction of their cleavage sites. Protein Eng Des Sel 10:1-6.

Pan D, He N, Yang Z, Liu H and Xu X (2005) Differential gene expression profile in hepatopancreas of WSSV-resistant shrimp (Penaeus japonicus) by suppression subtractive hybridization. Dev Comp Immunol 29:103-112.

Perona JJ and Craik CS (1995) Structural basis of substrate specificity in the serine proteases. Protein Sci 4:337-360.

Qin C, Chen L, Qin JG, Zhao D, Zhang H and Wu P (2009) Characterization of a serine proteinase homologous $(\mathrm{SPH})$ in Chinese mitten crab Eriocheir sinensis. Dev Comp Immunol 34:14-18

Rawlings ND, Morton FR, Kok CY, Kong J and Barrett AJ (2008) MEROPS: The peptidase database. Nucleic Acids Res 36:320-325.
Ross J, Jiang H, Kanost MR and Wang Y (2003) Serine proteases and their homologs in the Drosophila melanogaster genome: An initial analysis of sequence conservation and phylogenetic relationships. Gene 304:117-131.

Samuel RI and Reynolds SE (1993) Molting fluid enzymes of the tobacco hornworm Manduca sexta: Timing of proteolytic and chitinolytic activity in relation to preecdysial development. Arch Insect Biochem 24:33-44.

Sellos D and Wormhoudt A (1992) Molecular cloning of a cDNA that encodes a serine protease with chymotryptic and collagenolytic activities in the hepatopancreas of the shrimp Penaeus vanameii (Crustacea, Decapoda). FEBS Lett 309:219-224.

Sellos D and Wormhoudt A (1999) Polymorphism and evolution of collagenolytic serine protease genes in crustaceans. Biochim Biophys Acta 1432:419-424.

Serrano AE (2013) Ontogenetic changes in the activity of chymotrypsin and carboxypeptidases A and B in mud crab, Scylla serrata. Isr J Aquacult-Bamid 65:1-6.

Shi XZ, Zhao XF and Wang JX (2008) Molecular cloning and expression analysis of chymotrypsin-like serine protease from the Chinese shrimp, Fenneropenaeus chinensis. Fish Shellfish Immunol 25:589-597.

Southan C (2001) A genomic perspective on human proteases as drug targets. Drug Discov Today 6:681-688.

Swift GH, Craik CS, Stary SJ, Quinto C, Lahaie RG, Rutter WJ and MacDonald RJ (1984) Structure of the two related elastase genes expressed in the rat pancreas. J Biol Chem 259:14271-14278.

Szabo R and Bugge TH (2008) Type II transmembrane serine proteases in development and disease. Int J Biochem Cell B 40:1297-1316.

Ye HH, Tao Y, Wang GZ, Lin QW, Chen XL and Li SJ (2011) Experimental nursery culture of the mud crab Scylla paramamosain (Estampador) in China. Aquacult Int 19:313-321.

Zhao ZY, Yin ZX, Weng SP, Guan HJ, Li SD, Xing K, Chan SM and He JG (2007) Profiling of differentially expressed genes in hepatopancreas of white spot syndrome virus-resistant shrimp (Litopenaeus vannamei) by suppression subtractive hybridization. Fish Shellfish Immunol 22:520-534.

Zhou LM, Wu SG, Liu DC, Xu B, Zhang XF and Zhao BS (2012) Characterization and expression analysis of a trypsin-like serine protease from planarian Dugesia japonica. Mol Biol Rep 39:7041-7047.

Zhu L, Song LS, Mao YZ, Zhao JM, Li CH and Xu W (2008) A novel serine protease with clip domain from scallop Chlamys farreri. Mol Biol Rep 35:257-264.

\section{Internet Resources}

ORF Finder, http://www.ncbi.nlm.nih.gov/gorf (July 3, 2013).

NCBI, http://www.ncbi.nlm.nih.gov (July 3, 2013).

Expasy, http://www.expasy.ch/(July 3, 2013).

SignalP 4.0 software, http://www.cbs.dtu.dk/services/SignalP (July 3, 2013).

ClustalW, http://www.ebi.ac.uk/Tools/msa/clustalw2/.

\section{Associate Editor: Juan Lucas Argueso Almeida}

License information: This is an open-access article distributed under the terms of the Creative Commons Attribution License, which permits unrestricted use, distribution, and reproduction in any medium, provided the original work is properly cited. 